\title{
О некоторых правовых аспектах международного управления природными ресурсами
}

Василенко E. . $^{*}$

Исследовано понятие институционального механизма международного управления, формирование которого во многом связано с необходимостью эффективного разрешения природоресурсных споров, а также формированием и обогащением концепции устойчивого развития в свете планирующегося проведения Конференции по устойчивому развитию 2012 года. Освещены вопросы деятельности международных межправительственных организаций и международных судебных учреждений в сфере освоения, разведки и эксплуатации природных ресурсов.

Ключевые слова: международное управление; природные ресурсы; устойчивое развитие.

Международно-правовое регулирование отношений по поводу установления правового режима, освоения, разведки и эксплуатации природных ресурсов является комплексным, межотраслевым институтом международного права, развитие которого в последние десятилетия привело к формированию понятия «международное управление природными ресурсами». Целью данной статьи является анализ деятельности международных межправительственных организаций и международных судебных органов для обоснования доводов о том, что они формируют институциональный механизм международного управления. Актуальность исследования объясняется усилением наднациональных начал в современном международном праве и тем фактом, что «международное управление, осуществляемое с помощью наднационального решения международной организации, на порядок выше, чем «обычное» (нередко весьма ненадежное) договорное управление, и принципиально отличается от него ${ }^{1}$.

\footnotetext{
* Василенко Екатерина Владимировна - соискатель кафедры международного права юридического факультета Южного федерального университета. sfedu12@ya.ru.

1 Малеев Ю.Н. Новое международное право? / Сборник материалов научно-практической конференции, посвященной 60-летию кафедры международного права МГИМО (У) МИД России. М., 2010. С. 179.
} 
Прежде чем осветить правовые аспекты природоресурсной деятельности на институциональном уровне, следует отметить, что понятие международного управления является центральным во многих научных работах последних лет как российских ${ }^{2}$, так и зарубежных ${ }^{3}$ специалистов в области международного права.

Как отмечает Ю.Н. Малеев, управление природными ресурсами представляет собой процесс планирования, организации, мотивации и контроля использования природных ресурсов для достижения цели устойчивого развития ${ }^{4}$.

Е.Ф. Гладун конкретизирует общее управление природными ресурсами, раскрывая понятие механизма управления природными ресурсами как совокупности средств воздействия на природные ${ }^{5}$. При этом она осуществляет не вполне обоснованную классификацию «механизмов управления», называя в качестве обособленных категорий правовой, информационный, организационный, административный, экономический, общественный, международный, идеологический механизмы управления. В свою очередь, в каждый механизм входят свои «инструменты управления». Например, в рамках административного механизма автор учебного пособия выделяет лицензирование, экологическое нормирование, стандартизацию, оценку воздействия на окружающую среду, экологическую экспертизу ${ }^{6}$. На наш взгляд, такое деление приводит к излишней структурированности без учета взаимозависимости социальных норм. Даже выделенные административные инструменты нельзя отнести к исключительно административным - к примеру, стратегическую экологическую оценку, которая является важным средством учета экологических и экономических интересов и процесс проведения которой закреплен в Протоколе по стратегической экологической оценке и Конвенции об оценке воздействия на окружающую среду в трансграничном контексте.

А.Н. Вылегжанин указывает на новизну понятия международного управления, напоминая, впрочем, о факте широкого освещения данного

${ }^{2}$ См. например: Международно-правовые основы управления морскими живыми ресурсами. Теория и документы. / А.Н. Вылегжанин, В.К. Зиланов. М., 2000.

3 Benvenisti E. Asian Traditions and Contemporary International Law on the Management of Natural Resources Chinese Journal of International Law, Vol. 7, No. 2, pp. 273-283, 2008.

4 Там же.

5 Гладун Е.Ф. Управление природными ресурсами. Учебное пособие. Тюмень, 2007. C. 33.

6 Там же. С. 134. 
термина в работах Ф.Ф. Мартенса ${ }^{7}$. Последний еще в 1899 году давал трактовку данного термина, указывая на то, что это выражение «совсем неупотребительно у писателей международного права и совершенно ими не понимается... Право международного управления постоянно развивается как административными распоряжениями, так и законодательными постановлениями и в особенности международными соглашениями». Такое определение в первую очередь характеризует именно межгосударственное управление на основе международного договора. Однако даже в данный период ученый указывал на то, что «государства в области международного управления являются также сознательными органами высшей организации - международного общения» ${ }^{8}$. Это, на наш взгляд, является предпосылкой формирования понятия институционального международного управления, осуществляемого международными межправительственными организациями, а также международными судебными органами.

Международные межправительственные организации, как субъекты международного права, опосредуют волю государств, включая в свою структуру органы, занимающиеся управлением природными ресурсами либо являясь организациями специальной компетенции, чья деятельность направлена исключительно на развитие сотрудничества в сфере рационального ресурсопользования и охраны окружающей среды.

Так, ООН, как универсальная организация общей компетенции, распределяет свою природоресурсную деятельность в зависимости от ее экологической, экономической, социально-культурной составляющей между главными и вспомогательными органами, а также специализированными учреждениями (ФАО, ИМО, МАГАТЭ, ВОЗ, ЮНЕСКО и т.д.).

Одной из особенностей институционального механизма управления природными ресурсами является наличие большого числа программных документов, составляющих основу институционального сотрудничества, но нередко нуждающихся в консолидации. На примере ООН главной программой, направленной на развитие природоохранного сотрудничества, является ЮНЕП (Программа ООН по окружающей

\footnotetext{
7 Вылегжанин А.Н. Юридические начала управления живыми ресурсами Мирового океана. В кн.: Вылегжанин А.Н., Зиланов В.К. Международно-правовые основы управления морскими живыми ресурсами. М., 2000. С. 12-13.

${ }_{8}$ Мартенс Ф.Ф. Современное международное право цивилизованных народов. Т. 2 / Под ред. В.А. Томсинова. М.: Зерцало, 2008. С. 7.
} 
среде). Правовая природа ЮНЕП вызывает дискуссии в научных кругах. Профессор М.Н. Копылов, авторитетный специалист в области международного экологического права, придерживается единственно верной и юридически обоснованной точки зрения: «Несмотря на то, что ЮНЕП... - пишет М.Н. Копылов, - традиционно квалифицируется как международная организация особого рода, она такой, строго говоря, не является. И в рамках системы ООН такая международная экологическая организация, несомненно, должна быть создана» 9 .

Наличие надгосударственного подхода на региональном уровне и действенность такого подхода при реформировании механизма международного управления связывается с созданием Европейского союза. Особенности институционального управления в ЕС ставят вопрос о принадлежности норм, издаваемых Европарламентом, и правовой природе решений исполнительных органов ЕС, о том, что представляет собой европейское право и входит ли Евросоюз в институциональный механизм международного управления природными ресурсами. ${ }^{10}$

Если европейское право является «третьей системой права», законодательная и административная деятельность Евросоюза, определяющая правовые режимы освоения, эксплуатации и охраны природных ресурсов для государств - членов ЕС не относится к международному управлению. Тогда можно сделать вывод о том, что ЕС формирует институциональный механизм управления, но только в процессе взаимодействия с государствами, не являющимися его участниками. Это приводит к двойственности и неоднозначности и, в свою очередь, является доводом для того, чтобы выделять в качестве третьей системы права не европейское, а транснациональное право. Данная позиция, не раз аргументированная видными учеными-международниками ${ }^{11}$, разработана весьма детально, хотя зачастую требует дополнительного обоснования в части вопроса о соотношении транснационального и международного частного права.

\footnotetext{
9 Копылов М.Н. Право на развитие и экологическая безопасность развивающихся стран: Международно-правовые вопросы. Монография. М., ЭКОН. 2000. С. 166-167. 10 Международно-правовой характер сотрудничества ЕС как надгосударственного образования с государствами, не являющимися его членами, в данном случае не оспаривается. В данном случае речь идет о сотрудничестве субъектов международного права, действующих и принимающих решение на основе международно-правовых норм.

${ }^{11}$ См. например: Jessup P.P. Transnational Law. New Haven. 1956, Моисеев А.А. Надгосударственность в современном международном праве. М.: Научная книга, 2007.
} 
Отметим, что Евросоюз активно использует понятие «управление природными ресурсами». Если мы обратимся к решению Европейского парламента и Совета № 1600/2002/ЕС от 22 июля 2002 года о Шестой программе действий Сообщества в области окружающей среды, то обнаружим, что использование рассматриваемого термина производится в нем повсеместно: «управление природными ресурсами», «управление водами», «управление лесами» и т.д. Кроме того, термин «международное управление природными ресурсами», как и «устойчивое развитие», является междисциплинарной категорией, в связи с чем необходимо выделить правовые аспекты управления - например, при рассмотрении деятельности международных судебных учреждений. Помимо того, что их решения разрешают конкретный спор по существу, они, как и нормы мягкого права, обладают большой морально-политической силой и, главное, являются вспомогательными источниками международного права. Таким образом, международное управление природными ресурсами осуществляют:

1) международные суды, универсальные и региональные: Международный суд ООН, Международный трибунал по морскому праву, Орган по разрешению споров ВТО, Экономический суд СНГ, Суд ЕС и т.д.;

2) международный арбитраж - на постоянной основе или создаваемый для рассмотрения конкретного дела (ad hoc): Постоянная Палата Третейского суда, Международный экологический суд арбитража и примирения и т.д.

Названные судебные и третейские (арбитражные) органы, по мнению М.К. Сеггер и К. Вирамантри, формируют основу институциональной системы «устойчивого правосудия» ${ }^{12}$. При этом основными признаками, отличающими арбитражное разбирательство от судебного, являются меньшая формализованность, применимость к более широкому кругу участников и международных споров ${ }^{13}$.

Разветвленная система судебных органов, разрешающая споры, связанные с устойчивым ресурсопользованием и охраной природных ресурсов, приводит к институциональной фрагментации. А конкуренция экологических, экономических и иных международно-правовых норм,

${ }^{12}$ Segger M., Weeramantry C. Sustainable Justice: Reconciling Economic, Social and Environmental Law. Boston, 2005. P. 506.

${ }_{13}$ Попков А.Н. Формы международного арбитража и современные тенденции их развития в международном праве // Белорусский журнал международного права и международных отношений. № 3. 1998. С. 10-16. 
регулирующих рассматриваемые отношения, приводит к фрагментации правовых режимов и норм материального международного права.

Данный термин получил распространение в связи с включением в долгосрочную программу работы ООН в 2002 году темы «Риск фрагментации международного права», которая после формирования Исследовательской группы получила формулировку «Фрагментация международного права: трудности, обусловленные диверсификацией и расширением сферы охвата международного права».

Предметом споров, рассматриваемых Международным судом ООН и связанных с вопросами разведки и эксплуатации природных ресурсов, выступают отношения по поводу национализации, делимитации границ и условий концессионных соглашений недропользования.

Особый теоретический и практический интерес представляет дело об Англо-Иранской нефтяной компании. Великобритании подала жалобу на Иран по поводу национализации иранским правительством англо-иранской нефтяной компании. Иран заявил о неподсудности этого вопроса Международному Суду. Суд также признал неподсудность этого спора и не принял дело к рассмотрению.

Суд не согласился с утверждением о «двойственной природе» соглашения с Англо-Иранской нефтяной компанией: с одной стороны, концессионное соглашение, с другой - договор между двумя правительствами $^{14}$. Однако Суд заявил, что данное соглашение является «не более чем концессионным соглашением между правительством и иностранной корпорацией. Правительство Соединенного Королевства не является стороной контракта, который не устанавливает связь между обоими правительствами и никоим образом не регулирует отношения между ними. В соответствии с этим контрактом Иран не может предъявлять Соединенному Королевству какие-либо претензии, которые он может предъявлять компании; аналогичным образом и от Ирана нельзя требовать выполнения каких-либо обязательств в отношении Соединенного Королевства, которые он обязан выполнить в отношении компании. Эту ситуацию не изменяет тот факт, что контракт был заключен через посредство добрых услуг Совета Лиги Наций.

Еще одним органом, осуществляющим судебный контроль и, следовательно, международное управление природными ресурсами, является Международный трибунал по морскому праву. Рассмотренные дела (включая три дела, находящиеся в производстве) посвящены:

${ }^{14}$ The Anglo-Iranian Oil Co. case (United Kingdom v. Iran). ICJ Reports, 1952. P. 112. 
- задержанию и аресту иностранных морских судов, обеспечению соблюдения требований Конвенции о незамедлительном освобождении судна или его экипажа после предоставления залога или иного финансового обеспечения ${ }^{15}$. Заявления государств о рассмотрении государством дел об освобождении судна от ареста составляют большинство в практике Трибунала. Отметим, что природные ресурсы не являются предметом данной категории споров, поэтому их нельзя назвать природоресурсными. Однако главным фактором, составляющим мотив правонарушения, вследствие которого происходит арест иностранного судна, является незаконная добыча морских живых ресурсов в исключительной экономической зоне другого государства в нарушение Конвенции 1982 года и других действующих договоренностей;

- правам и обязанностям государств в области охраны живых ресурсов $^{16}$. К данной категории дел, рассмотренных Трибуналом, мы относим Дело о южном голубом тунце и Дело о сохранении и устойчивой эксплуатации запасов меч-рыбы в юго-восточной части Тихого океана. Данные дела наглядно иллюстрируют тот факт, что вопросы применения принципа устойчивого развития при добыче природных ресурсов остаются неурегулированными. Споры данной категории носят природоресурсный характер, то есть касаются применения судами при вынесении решения норм международного права, регулирующих отношения по освоению и эксплуатации природных ресурсов. Дело о рыбе-меч сопровождалось жалобой Европейского союза в ВТО по поводу запрета чилийскими властями производить разгрузку испанских рыболовных судов в портах Чили. Подобный запрет государство объясняло фактом нарушения Испанией правовых норм национального законодательства Чили по сохранению рыбы-меч и ее устойчивому использованию. ЕС утверждал, что законодательство Чили в данной области противоречит ГАТТ 1994 года, в частности статьям V и XI.

Урегулировать разногласия сторон удалось посредством заключения соглашения о научно-техническом сотрудничестве и договоренности

${ }^{15}$ См., например: The "Tomimaru" Case (Japan v. Russian Federation) Judgment. 6 August 2007, The M/V "Louisa" Case (Saint Vincent and the Grenadines v. Kingdom of Spain) Order 2011/2. 28 April 2011, The M/V “Virginia G” Case (Panama/Guinea-Bissau) Order of 2011/3. 18 August 2011// URL: http: www.itlos.ru (дата обращения 13.10.2011).

${ }^{16}$ Cases № 3, 4: Southern Bluefin Tuna Cases (New Zealand v. Japan; Australia v. Japan), Provisional Measures. 27 August 1999, Case concerning the Conservation and Sustainable Exploitation of Swordfish Stocks in the South-Eastern Pacific Ocean (Chile / European Union) // URL: http://www.itlos.org (дата обращения 13.10.2011). 
о выработке многостороннего соглашения об устойчивом использовании и сохранении рыбы-меч. Поскольку стороны разрешили разногласия, разбирательство в ВТО и Трибунале было прекращено. На наш взгляд, такой способ разрешения противоречий между субъектами МП, как принятие новых двусторонних договоров, не может считаться наиболее оптимальным и эффективным, поскольку нормы таких договоров не устраняют коллизии между универсальными нормами и принципами, более того - могут привести к последующим спорам о применении норм международного права;

- введению предварительных обеспечительных мер. Как правило, запрос о применении этой процедуры не является самостоятельным предметом спора, а представляет собой средство обеспечения интересов сторон на время рассмотрения дела. Исключение составляет спор между Малайзией и Сингапуром о мелиорации земель на побережье пролива Джохор ${ }^{17}$. В 2003 году Малайзией было возбуждено разбирательство в арбитраже, который должен быть сформирован в соответствии с Приложением VII к Конвенции 1982 года, по вопросу определения линии разграничения между территориальными морями государств у прибрежных островов. Рассмотрение дела по существу должно было осуществляться в международном арбитраже, однако на момент обращения в Трибунал он еще не был создан;

- обеспечению экологической безопасности. Спор, предмет которого наиболее точно соответствует выделенной категории, рассмотрен Международным трибуналом по морскому праву в Деле об атомной электростанции $\mathrm{MOKC}^{18}$. Вызвав широкие дискуссии, данное дело рассматривалось в рамках морского арбитража Постоянной палаты третейского суда и Судом Европейского союза, затронув проблему фрагментации МП, в первую очередь в части компетенции международных органов и применения конкурирующих норм международного и европейского права;

- территориальным спорам, в первую очередь спорам о делимитации морских границ; ${ }^{19}$

${ }^{17}$ Case concerning Land Reclamation by Singapore in and around the Straits of Johor (Malaysia v. Singapore), Provisional Measures. Order of 8 October 2003 //URL: http: www. itlos.ru (дата обращения 24.09.2011).

${ }^{18}$ The MOX Plant Case (Ireland v. United Kingdom), Provisional Measures. 3 December 2001 //URL: http: www.itlos.ru (дата обращения 13.10.2011).

${ }^{19}$ Dispute concerning delimitation of the maritime boundary between Bangladesh and Myanmar in the Bay of Bengal (Bangladesh/Myanmar) ITLOS/PV.11/14 22 September 2011 
- обязанностям и степени ответственности государств в отношении организационных аспектов деятельности в районе морского дна за пределами национальной юрисдикции.

Механизм разрешения природоресурсных споров Всемирной Торговой Организации, проистекающих из любого соглашения «пакета ВТО», а также порядок исполнения решений, принятых Органом по разрешению споров, отличается от порядка разрешения споров международными судами. Поэтому система разрешения споров в рамках Всемирной Торговой Организации не рассматривается как stricto sensо судебная.

Природоресурсные споры касаются ограничения или запрета импорта, которые обосновываются необходимостью охраны окружающей среды от негативного воздействия. Причем истцами могут выступать:

- государства, налагающие запрет или ограничение на импорт товаров; Такие дела рассматривались еще в рамках ГАТТ с 1948 по 1994 г., например о запрете импорта тунца и продуктов из тунца из Канады ${ }^{20}$; о мерах, затрагивающих экспорт необработанной сельди и лосося ${ }^{21}$; об ограничениях на импорт и внутреннее налогообложение сигарет ${ }^{22}$;

- государства, опротестовывающие запрет или ограничение и полагающие, что действия государства-ответчика противоречат праву ВТО. Примерами таких споров являются уже упомянутое нами дело о стандартах переработанного и обычного бензина; о запрете на импорт некоторых видов креветки и продуктов из креветки ${ }^{23}$; о мерах, затрагивающих импорт асбеста и асбестосодержащих товаров ${ }^{24}$.

Итак, центральное место в институциональном механизме управления природными ресурсами занимают международные судебные органы, в то время как решения международного арбитража, особенно создаваемого ad hoc, важны в первую очередь для участников спора и не вносят такого же значительного вклада в формирование механизма

//URL: http: www.itlos.ru (дата обращения 13.10.2011).

${ }^{20}$ United States - Prohibition of Imports of Tuna and Tuna Products from Canada, BISD 29S/91, (Feb. 22, 1982).

${ }^{21}$ Canada - Measures Affecting Exports of Unprocessed Herring and Salmon, BISD 35S/98 (March 22, 1988).

${ }^{22}$ Thailand - Restrictions on the Importation of and Internal Taxes on Cigarettes, BISD 37S/200 (Nov. 7, 1990).

${ }^{23}$ United States - Import Prohibition of Certain Shrimp and Shrimp Products, Appellate Body Report adopted by DSB, WT/DS58/AB/R (November 6, 1998).

${ }^{24}$ European Communities - Measures Affecting Asbestos and Asbestos-Containing Products, Appellate Body Report adopted by DSB, WT/DS135/ AB/R (April 5, 2001). 
природоресурсного управления. Вместе с тем стороны чаще выбирают арбитраж для разрешения природоресурсных, в первую очередь экологических, споров. Это объясняется активной деятельностью международного арбитража в сфере разрешения и предотвращения природоресурсных споров - а именно Постоянной Палаты Третейского Суда и Международного Суда экологического арбитража и примирения.

ППТС, созданная в соответствии со ст. 41 Конвенции о мирном разрешении международных столкновений 1899 года, inter alia, paзрабатывает правила разрешения споров, возникающих в процессе освоения и эксплуатации природных ресурсов, а также принимает специальные процедурные регламенты:

- Примерный Регламент ППТС по арбитражному разбирательству споров, связанных с природными ресурсами и/или окружающей средой от 19 июля 2001 года (на основе Арбитражного регламента ЮНСИТРАЛ);

- Примерный согласительный регламент ППТС по урегулированию споров, связанных с природными ресурсами и/или окружающей средой от 16 апреля 2002 года (на основе Согласительного регламента ППТС и Согласительного регламента ЮНСИТРАЛ).

Также ППТС предоставляет «административную поддержку» другим международным арбитражным органам. Например, Дело о базальтовом карьере в Новой Шотландии (Bilcon of Delaware et al v. Government of Canada): компания Bilcon и заинтересованные физические лица в 2008 году обратились в арбитраж с целью взыскать с правительства Канады 188 млн долларов США в качестве ущерба за дискриминационные меры, предпринятые Канадой в нарушение условий предоставления национального режима и режима наибольшего благоприятствования, предусмотренных главой 11 Североамериканского соглашения о свободной торговле (НАФТА). Данная глава обеспечивает иностранным инвесторам защиту от произвольных и необоснованных действий органов государственной власти и закрепляет механизм разрешения споров для инвесторов.

Инвестором было получено разрешение на строительство базальтового карьера, использование морского терминала для транспортировки оборудования и последующую добычу базальта в Новой Шотландии (Канада). В соответствии с законодательством Канады любое промышленное освоение должно осуществляться на основе предварительной экологической оценки перед строительством и эксплуатацией 
объектов. При этом процедуры экологической экспертизы определяются в зависимости от масштаба проекта и характера предполагаемого воздействия на окружающую среду. Представитель инвестора Барри Эпплтон в уведомлении об арбитражном разбирательстве отметил, что экологические нормы и инвестиционный режим применялись к инвестору «произвольным, дискриминационным и несправедливым образом» ${ }^{25}$. В уведомлении отмечается, что «процесс, в рамках которого органы государственной власти проводили экологическую оценку, был надуманным, не транспарентным, с многочисленными нарушениями правил, норм, процедур и общих предписаний, регулирующих экологическую оценку. В результате процесс оказался чрезмерно запутанным и растянулся на длительный срок - более 5 лет» ${ }^{26}$. По утверждению заявителя, экологическая экспертиза оказалась чрезмерно дорогой по сравнению с оценкой, проводимой в отношении других инвесторов и проектов. Поэтому предпринятые меры оценки оказались дискриминационными, принципиально несправедливыми и нанесли ущерб в размере 188 млн долларов США. Канада нарушила ст. 1103 НАФТА, в соответствии с которой иностранному инвестору государства - участника НАФТА должен предоставляться режим не менее благоприятный, чем любой другой стороне из государства, не являющегося участником соглашения.

В споре, приведенном нами в качестве примера, широко применяются инвестиционные и экологические нормы, в связи с чем необходимо упомянуть о получившей распространение в научных кругах концепции о необходимости создания Международного экологического суда, который разрешал бы по существу все экологические споры во всем их многообразии. М.Н. Копылов и А.М. Солнцев отмечают: «Если Международный экологический суд будет создан, то потребуются пересмотр и внесение изменений в международные экологические соглашения. Международный экологический суд должен будет либо стать структурной единицей ООН, либо иметь связь с ООН по аналогии с Международным уголовным судом» ${ }^{27}$.

${ }^{25}$ Notice of Arbitration under the Arbitration Rules of the United Nations Commission on International Trade Law and the North America Free Trade Agreement. Claytons\&Bilcon of Delaware, INC. v. Government of Canada. May, 26. 2008. p. 3 // http://www.pca-cpa.org/ upload/files/ BilconNoticeofArbitration.pdf (дата обращения: 13.10.2011).

${ }^{26}$ Там же. Р. 10.

${ }^{27}$ Копылов М.Н., Солнцев А.М. Международное экологическое право на пороге реформ // Московский журнал международного права. 2010. № 1. С. 126. 
На наш взгляд, именно повышение эффективности неюрисдикционных средств разрешения природоресурсных споров (согласительных комиссий, обращений в региональные организации, дипломатических средств) является приоритетным по сравнению с созданием универсального экологического суда. Решения международных судов подтверждают исключительную важность переговорного процесса и применения досудебных (или применяющихся одновременно с рассмотрением дела по существу) мирных средств разрешения природоресурсных споров. Так, в деле о континентальном шельфе Эгейского моря Международный суд отказался применять временные меры, препятствующие Турции в проведении ее морских исследований и разведки в районе островов, находящихся в территориальной близости к Турции и также являющихся предметом спора. Суд посчитал, что такие меры могут усложнить процесс переговоров, а также войти в противоречие с обязанностью, подчеркнутой в специальной Резолюции Совета Безопасности ООН 395 от 25 августа 1976 года, использовать все возможные средства и методы мирного урегулирования споров и уважать права и обязательства друг друга с целью недопущения эскалации конфликта. Более того, Суд указал, что при принятии названной езолюции СБ ООН, стороны в лице своих представителей поддержали идею продолжения прямых переговоров по данному вопросу, указав, что это соответствует их интересам ${ }^{28}$.

Активно развивающееся европейское право содержит институт вынесения преюдициальных заключений, играющих важную роль в функционировании европейской правовой системы и демонстрирующих эффективность смешанного подхода: применение юрисдикционных средств вкупе с консультативным заключением. На наш взгляд, использование этого института при разрешении международных природоресурсных споров было бы весьма целесообразным в случае, если назревшее реформирование Международного Суда ООН состоится. При смешанном подходе на любом этапе рассмотрения дела по существу судебный или арбитражный орган сможет приостановить разбирательство и обратиться в Международный суд ООН с целью разъяснить толкование норм, которые подлежат применению, в том числе о подсудности данного дела суду.

\footnotetext{
${ }^{28}$ Agean Sea Continental Shelf Case (Greece v. Turkey) / Request for the Indication of Interim Measures of Protection, Order of 11 September 1976, paras. 38-41.
} 
В настоящее время реализовать преюдициальную международную судебную практику посредством предоставления МС ООН консультативных заключений невозможно. Хотя ст. 96 Устава ООН к общим полномочиям Международного суда относит дачу консультативных заключений по вопросам международного права, однако такие запросы могут поступать только от органов ООН, наделенных такими полномочиями (Генеральной Ассамблеи, Совета Безопасности, специализированных учреждений).

В целом рассмотренные предложения и международно-правовые средства повышения эффективности природоресурсного управления сопряжены со значительными трудностями правового и организационного характера, а также с тем фактом, что создание и изменение международно-правовых норм, касающихся правовых режимов освоения и эксплуатации природных ресурсов, требует выражения согласия на обязательность таких норм со стороны государств-членов. Это возможно только в процессе созыва международной конференции, которая должна будет не только рассмотреть вопросы защиты окружающей среды, но и пересмотреть основы природоресурсного сотрудничества в целом, поскольку ООН закрепляет межгосударственное сотрудничество и не обладает свойством наднациональности. В связи с этим одним из наиболее актуальных вопросов возможного реформирования институционального механизма природоресурсного управления является эффективность подготовки к Конференции ООН по устойчивому развитию 2012 года. Как указывает одна из ведущих российских некоммерческих организаций ${ }^{29}$, саммит будет посвящен четырем вопросам: обзору хода выполнения предыдущих обязательств в области устойчивого развития, новым проблемам, экологизации экономики в контексте ликвидации нищеты и устойчивого развития, институциональной базе устойчивого развития.

\section{Библиографический список}

Вылегжанин А.Н., Зиланов В.К. Международно-правовые основы управления морскими живыми ресурсами. Теория и документы. M., 2000.

Гладун Е.Ф. Управление природными ресурсами. Учебное пособие. Тюмень, 2007.

${ }^{29}$ Центр по проблемам окружающей среды и устойчивого развития «ЭКО-Согласие» [Электронный pecypc] http://www.ecoaccord.org/, (дата обращения 13.10.2011 года). 
Копылов М.Н. Право на развитие и экологическая безопасность развивающихся стран: Международно-правовые вопросы. Монография. М., ЭКОН. 2000.

Копылов М.Н., Солнцев А.М. Международное экологическое право напорогереформ//Московский журнал международногоправа. -2010.-№ 1.

Малеев Ю.Н. Новое международное право? - Сборник материалов научно-практической конференции, посвященной 60-летию кафедры международного права МГИМО (У) МИД России. Под. ред. проф. А.Н. Вылегжанина. М. 2010.

Мартенс Ф.Ф. Современное международное право цивилизованных народов. Т. 2. / Под ред. В.А. Томсинова. М., ЗЕРЦАЛО, 2008.

Моисеев А.А. Надгосударственность в современном международном праве. М.: Научная книга. 2007.

Попков А.Н. Формы международного арбитража и современные тенденции их развития в международном праве // Белорусский журнал международного права и международных отношений. № 3, 1998.

Benvenisti E. Asian Traditions and Contemporary International Law on the Management of Natural Resources Chinese Journal of International Law, Vol. 7, No. 2, 2008.

Jessup P.P. Transnational Law. New Haven. 1956.

Segger M., Weeramantry C. Sustainable Justice: Reconciling Economic, Social and Environmental Law. Boston, 2005. 


\section{Some Legal Issues in Natural Resources' International Management (Summary)}

Ekaterina V. Vasilenko*

The article examines the concept of international governance which is largely due to the efficiency of natural resources dispute settlement, supranational phenomenon in contemporary international law, formation and enrichment of the concept of sustainable development in light of the planned Conference on Sustainable Development in 2012. The author highlights the important issues in activities of international governmental organizations and international judicial institutions related to natural resources exploration, prospecting and exploitation.

Keywords: International management; natural resources; sustainable development.

* Ekaterina V. Vasilenko - postgraduate student of the Chair of International law of the Faculty of Law, Southern Federal University. sfedu12@ya.ru. 